\title{
Doped-carbazolocarbazoles as hole transporting materials in small molecule solar cells with different architectures.
}

\author{
David Curiel,,${ }^{\mathrm{a}} \mathrm{b} *$ Miriam Más Montoya, ${ }^{\mathrm{a}}$ Markus Hummert, ${ }^{\mathrm{b}, \mathrm{c}}$ Moritz Riede ${ }^{\mathrm{b}, \mathrm{d}} *$ and \\ Karl Leo ${ }^{b} *$ \\ ${ }^{a}$ Department of Organic Chemistry, Faculty of Chemistry, University of Murcia, Campus of Espinardo, 30100 \\ Murcia,Spain; davidcc@um.es; Tel.+34868888389 \\ ${ }^{b}$ Institut für Angewandte Photophysik, Technische Universität Dresden, George-Bähr Str. 1, D-01069 Dresden, \\ Germany: karl.leo@iapp.de;Tel. +4935146334389 \\ ${ }^{c}$ Current address: Novaled GmbH, Tatzberg 49, 01307 Dresden, Germany. \\ ${ }^{d}$ Current address: Department of Physics, University of Oxford, Clarendon Laboratory, Parks Road, Oxford, OX1 \\ 3PU, United Kingdom; moritz.riede@physics.ox.ac.uk; Tel. +44 1865272377
}

\begin{abstract}
The adaptation of interfacial layers to the stacked architecture of organic solar cells represents a very useful strategy for improved device operation. In this context, heteroacenic structures such as carbazolocarbazoles have been doped and evaluated as hole transporting materials in small molecule solar cell with either inverted or conventional architecture. S-kinks in the IV-curve detected for the inverted solar cells could be remarkably corrected by reversing the deposition sequence, highlighting the importance of buffer layer adjustment. Some of the studied carbazolocarbazoles proved to be a suitable molecule to be used as hole transporting materials.
\end{abstract}

\section{Introduction.}

The intensive research on the understanding and the optimisation of the performance of organic solar cells has rendered excellent results[1-9] which have made organic photovoltaics into a potential alternative within the area of solar energy. Nevertheless, the critical aspect limiting a faster progress in organic solar cells is due to the inherent difficulty of the charge carrier generation and transport in conjugated organic materials[10, 11]. This topic becomes even more relevant when considering the typical multilayer architecture where several materials are combined for the fabrication of an organic solar cell. The multilayer design covers from the simple two component device, with either a flat or a bulk heterojunction[12,13], going through the incorporation of anode and cathode buffer layers[14], to eventually arrive at the more sophisticated tandem solar cells[15]. Going back to the problem of charge transport, the stacked structure of organic photovoltaic devices involves not only the charge transport within a certain material, but even more challenging, , the charge transfer at the interface between different materials, namely electrode/organic[16-18], inorganic/organic[19, 20] or organic/organic heterojunctions[21, 22]. In this regard, the incorporation of interfacial hole and electron transporting layers has been proven to enhance organic solar cell operation owing to several reasons such as smoothing the electrode surface, protecting the active layer from the electrode, favouring the energy gradient for charge transport, blocking excitons and wrongly directed charge carriers, or acting as optical spacers[23-26].

The important role of these interfacial layers has led us to explore the use of recently described carbazolocarbazoles 1 and 2 (Figure 1) [27-29], as hole transporting materials (HTM) in small molecule organic solar cells. The electronic structure of carbazolocarbazoles, with appropriate HOMO and LUMO energies (Figure 2) and transparency to the visible radiation, makes them good candidates to be used as organic buffer layers. Besides, the two different $\mathrm{N}$-substituents on the carbazolocarbazole system will further enable the study of the correlation between the structure of the molecule and its adequacy to operate as HTM. Additionally, we also examined the effect of the solar cell architecture on the J-V characteristics by preparing devices with inverted and conventional structure.

\section{Materials and methods.}

Device fabrication was carried out in custom-made high-vacuum chambers at a base pressure of $10^{-6}$ to $10^{-7}$ mbar. The organic materials and the metal electrodes were thermally evaporated through different shadow masks which were exchanged without breaking the vacuum. Indium-tin oxide (ITO) coated glass with a sheet resistance of 30 $\Omega /$ sq. was used as transparent substrate. These substrates were cleaned by washing with acetone, ethanol, and then treating with oxygen plasma.

Both the inverted and the conventional solar cells were made by evaporating the following materials: carbazolocarbazoles 1 and $\mathbf{2}$ were used as hole transporting materials and were doped with 20\% wt. NDP9 (p-dopant produced by Novaled $\mathrm{GmbH}$ )[30] using a coevaporation protocol; indenoperylene derivative $\mathbf{3}$ was used as donor material and fullerene was used as acceptor material to build up a flat heterojunction active layer; in the solar cells with conventional architecture 4,7-diphenyl-1,10-phenanthroline (BPhen) 5 was used as cathode buffer; the devices were completed by thermally evaporating aluminium as top electrode. 
The solar cells were protected by an encapsulating glass glued and UV-cured under inert atmosphere. The overlapping region between the ITO and the top electrode defined a device active area of $6.4 \mathrm{~mm}^{2}$.

Current-voltage (J-V) characteristics were scanned using a source measurement unit (Keithley) and a sun simulator (SC 1200, KHS Technical Lighting, Germany) to reproduce the standard terrestrial solar spectra at AM 1.5G. Measurements were monitored by a Hamamatsu S1337 silicon photodiode (calibrated by Fraunhofer ISE) used as reference for the intensity values. The reported efficiency values are corrected for spectral mismatch.

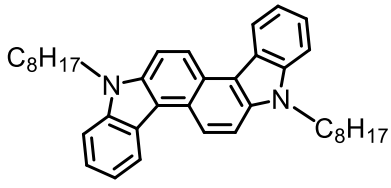

1

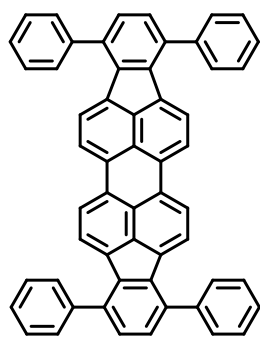

3

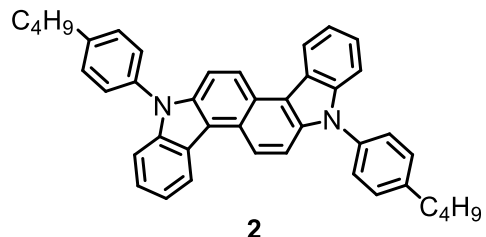

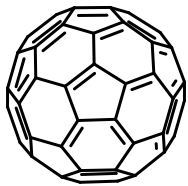

4

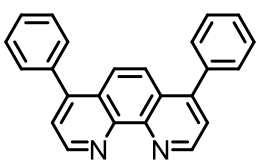

5

Fig. 1. Chemical structure of the used molecules.

\section{Results and discussion.}

Due to the benefits of molecular doping for the charge carrier transport in organic semiconductors[31, 32], preliminary lateral conductivity experiments were carried out by coevaporating the studied carbazolocarbazoles with NDP9. The gradual increase of the p-dopant/HTM ratio led to a noticeable improvement in the conductivity of the evaporated thin film as a result of the increased charge carrier concentration induced by the electron transfer process between the carbazolocarbazole and the p-dopant. Conductivity values of $2 \cdot 10^{-6} \mathrm{~S} / \mathrm{cm}$ for carbazolocarbazole $\mathbf{1}$ and $1 \cdot 10^{-8} \mathrm{~S} / \mathrm{cm}$ for compound 2 were measured for a dopant concentration of $10 \% \mathrm{w} / \mathrm{w}$. According to the very similar HOMO energies of these two materials, the difference in the observed conductivities should be related to the structure of the organic molecule. The different solid state packing of compounds $\mathbf{1}$ and $\mathbf{2}$ has been demonstrated to influence their charge mobility[27]. Additionally, it is likely that the 4-butylphenyl substituents in compound $\mathbf{2}$ cause steric hindrance which also makes more difficult the intermolecular close contact with the dopant and consequently affects the doping process.

Once it had been proven that carbazolocarbazoles could be doped with conductivities suitable to be used as hole transporting materials, they were integrated into the multilayer structure of small molecule solar cells. The flat heterojunction device with an inverted architecture (Figure 2) followed the sequence ITO / $\mathrm{C}_{60}(25 \mathrm{~nm}) /$ Indenoperylene-based donor (3; $25 \mathrm{~nm}) / \mathrm{p}-\mathrm{HTM}$ (1 or 2:NDP9; $40 \mathrm{~nm}) / \mathrm{NDP} 9$ (2 nm) / Al (100 nm). The J-V characteristics of these devices displayed a pronounced S-kink at forward bias around de $\mathrm{V}_{\text {oc }}$ value (Figure 2). Several causes have been related to the origin of S-kinks:[33] imbalanced mobilities,[34] interfacial dipoles[35], energy barriers either at the active layer[36-39] or at the electrodes[40], and charge transport limitation[41] are some of the studied phenomena. Anyhow, any of these causes translates into a charge accumulation within the device. In our particular case, since we were interested in the role of novel carbazolocarbazoles as hole transporting layers we analysed how this effects could manifest in the tested materials.
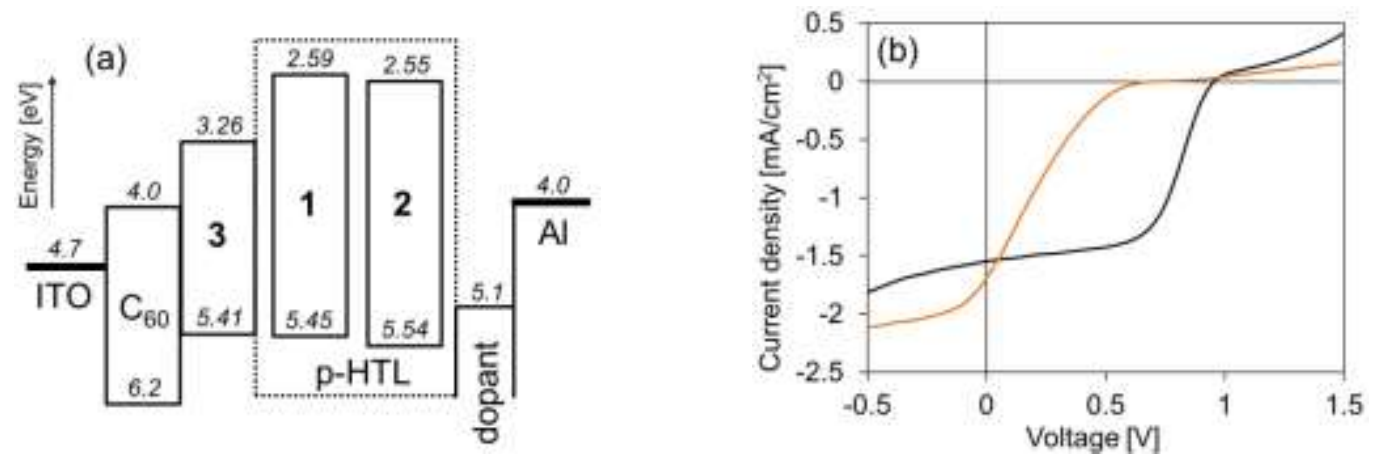

Fig. 2. (a) Sketch of the organic solar cell with inverted architecture and (b) J-V characteristics under illumination, $1.5 \mathrm{AM}, 100 \mathrm{~mW} / \mathrm{cm}^{2}$. (black: p-HTM 1; orange: p-HTM 2). 
The choice of indenoperylene $\mathbf{3}$ as donor material, with a HOMO energy of $-5.41 \mathrm{eV}$, contributed to a good energy level alignment at the organic/organic interface between the donor and the carbazolocarbazole, thus minimising the possible effect of energy barriers at this section of the device. Nevertheless, an energy level misalignment is evident at the anode interface. Additionally, as it could be inferred from the previously discussed conductivity measurements, problems related to the charge transport cannot be discarded for compound $\mathbf{2}$. Moreover, despite the presence of an ultrathin $(2 \mathrm{~nm})$ dopant layer, inserted to get ohmic contacts, and the p-doped carbazolocarbazoles, which should enhance the charge transfer at the p-HTL/Al interface by narrowing the width of the Schottky region, the evaporation of the top aluminium contact could have a detrimental effect on the hole transport layer. It is well known that metals evaporated on organic layers can penetrate into the organic materials affecting their electronic properties and their morphology[42-44]. In the particular case of aluminium it has been reported that it could even induce hole blocking[45].

As a consequence, using the same materials the evaporation sequence was reversed to prepare devices with a conventional architecture (Figure 3): ITO / NDP9 (2nm) / p-HTM (1 or 2:NDP9; $40 \mathrm{~nm}) /$ Indenoperylene-based donor $(3 ; 25 \mathrm{~nm}) / \mathrm{C}_{60}(25 \mathrm{~nm}) / \mathrm{BPhen}(6 \mathrm{~nm}) / \mathrm{Al}(100 \mathrm{~nm})$. In this case, the J-V characteristics improved and the previously detected $\mathrm{S}$-kinks were almost completely corrected.
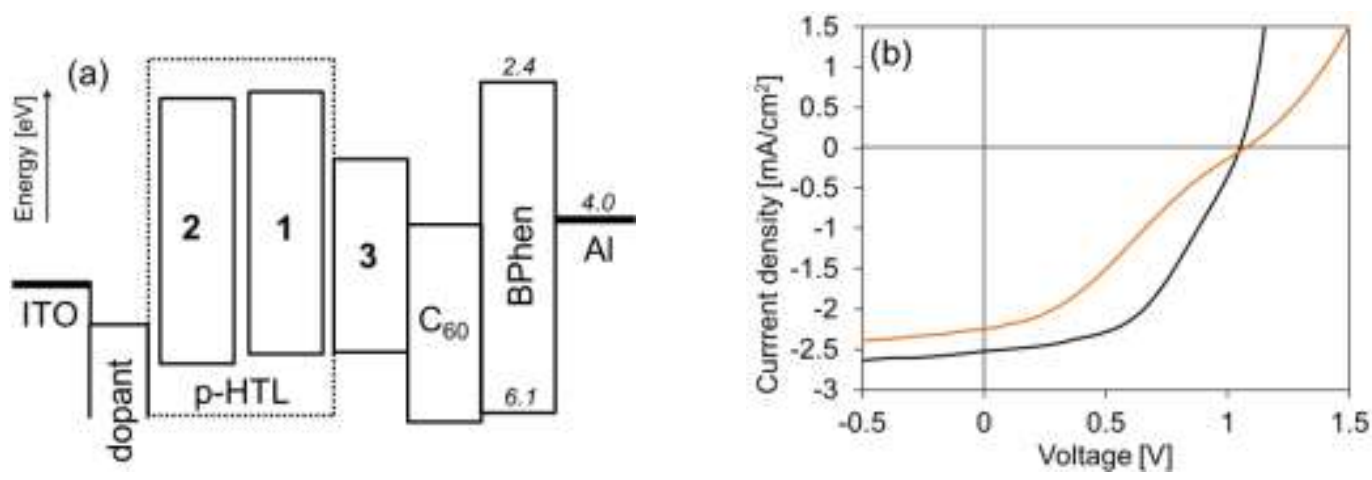

Fig. 3. Sketch of the organic solar cell with conventional architecture and $\mathrm{J}-\mathrm{V}$ characteristics under illumination, 1.5 $\mathrm{AM}, 100 \mathrm{~mW} / \mathrm{cm}^{2}$. (black: p-HTM 1; orange: p-HTM 2).

Table 1. Characterisation parameters of organic solar cells with inverted and conventional architectures.

\begin{tabular}{ccccc}
\hline \multicolumn{5}{c}{ Inverted architecture } \\
\hline HTM & $\mathrm{V}_{\mathrm{oc}}[\mathrm{V}]$ & $\mathrm{J}_{\mathrm{sc}}\left[\mathrm{mA} / \mathrm{cm}^{2}\right]$ & $\mathrm{FF}(\%)$ & $\eta(\%)$ \\
\hline $\mathbf{1}$ & 0.96 & 1.55 & 58.1 & 0.86 \\
$\mathbf{2}$ & 0.74 & 1.69 & 15.6 & 0.19 \\
\hline \multicolumn{5}{c}{ Conventional architecture } \\
\hline $\mathbf{1}$ & 1.05 & 2.52 & 49.5 & 1.31 \\
$\mathbf{2}$ & 1.07 & 2.25 & 31.2 & 0.75 \\
\hline
\end{tabular}

In agreement with the different results obtained for the inverted and the conventional devices, the presence of an energy barrier in the inverted devices can be concluded from the comparison of the dark current in the J-V plots (Figure 4). A negligible current can only be measured for the inverted devices. Thus, assuming here that the ITO/ $\mathrm{C}_{60}$ interface forms a good contact, the low current was ascribed to a hole injection barrier at the anode contact. Interestingly, a much higher current was observed for the devices with a conventional architecture. Again, considering that the common $\mathrm{C}_{60} / \mathrm{BPhen} / \mathrm{Al}$ combination behaves as a good contact, the better energy level alignment of the doped carbazolocarbazoles at the ITO side can improve the current flow.

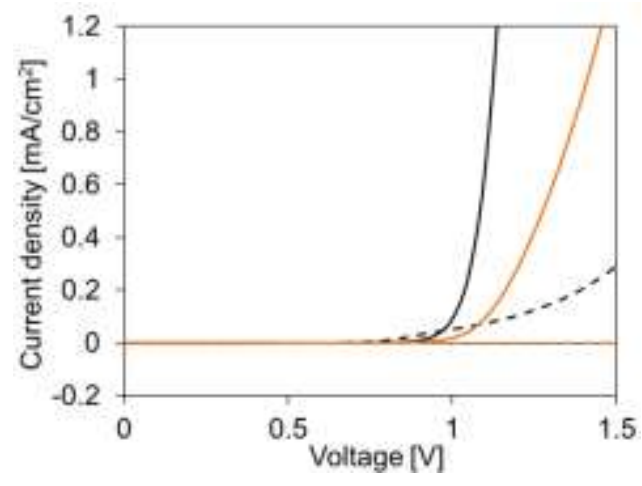

Fig. 4. J-V characteristics in the dark for organic solar cells with inverted architecture (dashed plot) and conventional architecture (continuous plot); (black: p-HTL 1; orange: p-HTL 2). 
Moreover, the double logarithmic representation of $\mathrm{J} v s\left(\mathrm{~V}-\mathrm{V}_{\mathrm{oc}}\right)$ further confirmed the charge accumulation within the solar cells with inverted architecture (Figure 5). A noticeable change in the slope of the plots, which is commonly attributed to a space charge limited (SCLC) transport model, was detected for those devices with Skinks[40]. In accordance with these results, the charge blocking, located at the p-HTL/Al interface in the devices with inverted architecture, corresponded well to a SCLC regime. Conversely, this behaviour was not that evident for the devices with conventional architecture.

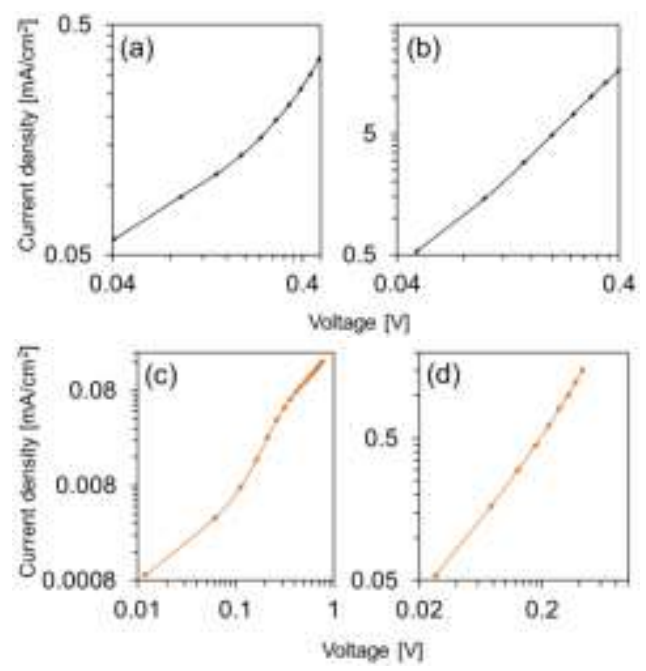

Fig. 5. Double logarithmic plot, J vs. V-V $\mathrm{V}_{\mathrm{oc}}$, for devices with inverted architecture (a) and (c), or conventional architecture (b) and (d) under illumination; (black: p-HTM 1; orange: p-HTM 2)

A comparison of the characterisation parameters (Table 1) for all the fabricated devices revealed that $\mathrm{V}_{\mathrm{oc}}$ was virtually independent on the architecture of the device and the material in the hole transporting layer, as it would be expected for a property basically determined by the energy difference between the HOMO of the donor and the LUMO of the acceptor in the active layer[46]. The lower $\mathrm{V}_{\mathrm{oc}}$ detected for the inverted device prepared with carbazolocarbazole 2 might result from a decreased surface recombination velocity[40] presumably correlated with a less efficient doping.

Regarding the $\mathbf{J}_{\mathrm{sc}}$ values, they neither showed a significant dependence on the carbazolocarbazole structure. Nevertheless, it is worth noticing that lower current densities were obtained for the inverted devices. As a result of the charge accumulation at the HTM/electrode interface, evidenced by the S-kinks, an internal electric field can originate. This in turn will restrain the charge extraction from the active layer which can promote the occurrence of recombination processes decreasing the current density.

As far as the fill factor is concerned, a clear influence of the structure of the material in the hole transporting layer is observed. Focusing on the solar cells with conventional architecture, the shape of the J-V characteristics displayed a much higher series resistance for the device prepared with carbazolocarbazole 2 than that prepared with compound $\mathbf{1}$, as it could be inferred from the slope $\left(1 / \mathrm{R}_{\mathrm{s}}\right)$ of a straight line that was adjusted to $\mathrm{J}-\mathrm{V}$ values close to the $\mathrm{V}_{\mathrm{oc}}$. Since the series resistance of a solar cell can have several causes (resistance of the organic materials and electrodes, resistance of the interfaces and probe resistance)[47] but the compared devices would only differ in the nature of the HTM, the J-V characteristics were in good agreement with the conductivity experiments.

Overall, the results obtained for the carbazolocarbazole $\mathbf{1}$ are certainly comparable to, or even better than those reported for similar solar cells prepared with well recognised hole transporting materials[37]. Accordingly, carbazolocarbazoles show promising properties to become useful hole transporting materials for the fabrication of organic electronic devices.

\section{Conclusions}

In summary, novel carbazolocarbazoles $\mathbf{1}$ and $\mathbf{2}$ have been tested as doped hole transporting materials in small molecule solar cells. The nature of the substituents attached to the nitrogen in the heteroacenic system have demonstrated to remarkably condition the hole transport ability of these molecules. This confirmed that, in addition to a good energy level correlation, when inserting interfacial layers their structure could be determinant. Small molecule solar cells with inverted and conventional architectures have been evaluated during the characterisation of the materials. The inverted devices showed S-kinks in the J-V curves due to charge blocking at the organic/anode interface. The good fill factor observed with compound $\mathbf{1}$ is indicative that an optimisation of the top contact interface may render better results. Besides, the S-kinks could be noticeably reduced by reversing the evaporation sequence for the fabrication of the solar cells. In this case, the observed improvement confirmed the aptitude of carbazolocarbazoles to be used as hole transporting materials in organic solar cells. 


\section{Acknowledgements}

Authors are grateful to the DFG for a Grant for the Initiation of an International Collaboration and to the Spanish Ministry of Science and Technology (Project CTQ-2011-27175). M. M.-M. acknowledges the Spanish Ministry of Education for a FPU fellowship.

\section{References}

[1] X. Guo, N. Zhou, S.J. Lou, J. Smith, D.B. Tice, J.W. Hennek, R.P. Ortiz, J.T.L. Navarrete, S. Li, J. Strzalka, L.X. Chen, R.P.H. Chang, A. Facchetti, T.J. Marks, Polymer solar cells with enhanced fill factors, Nat. Photon., 7 (2013) 825-833.

[2] V. Gupta, A.K.K. Kyaw, D.H. Wang, S. Chand, G.C. Bazan, A.J. Heeger, Barium: An Efficient Cathode Layer for Bulk-heterojunction Solar Cells, Sci. Rep., 3 (2013).

[3] Z. He, C. Zhong, S. Su, M. Xu, H. Wu, Y. Cao, Enhanced power-conversion efficiency in polymer solar cells using an inverted device structure, Nat. Photon., 6 (2012) 591-595.

[4] http://www.heliatek.com/.

[5] Y. Liu, C.-C. Chen, Z. Hong, J. Gao, Y. Yang, H. Zhou, L. Dou, G. Li, Solution-processed small-molecule solar cells: breaking the $10 \%$ power conversion efficiency, Sci. Rep., 3 (2013).

[6] J.A. Love, C.M. Proctor, J. Liu, C.J. Takacs, A. Sharenko, T.S. van der Poll, A.J. Heeger, G.C. Bazan, T.-Q. Nguyen, Film Morphology of High Efficiency Solution-Processed Small-Molecule Solar Cells, Adv. Funct. Mater., 23 (2013) 5019-5026.

[7] Y. Sun, G.C. Welch, W.L. Leong, C.J. Takacs, G.C. Bazan, A.J. Heeger, Solution-processed small-molecule solar cells with $6.7 \%$ efficiency, Nat. Mater., 11 (2012) 44-48.

[8] D.H. Wang, A.K.K. Kyaw, V. Gupta, G.C. Bazan, A.J. Heeger, Enhanced Efficiency Parameters of SolutionProcessable Small-Molecule Solar Cells Depending on ITO Sheet Resistance, Adv. Energy Mater., 3 (2013) 11611165.

[9] J. Zhou, X. Wan, Y. Liu, Y. Zuo, Z. Li, G. He, G. Long, W. Ni, C. Li, X. Su, Y. Chen, Small Molecules Based on Benzo[1,2-b:4,5-b']dithiophene Unit for High-Performance Solution-Processed Organic Solar Cells, J. Am. Chem. Soc., 134 (2012) 16345-16351.

[10] Y. Shirota, H. Kageyama, Charge Carrier Transporting Molecular Materials and Their Applications in Devices, Chem. Rev., 107 (2007) 953-1010.

[11] V. Coropceanu, J. Cornil, D.A. da Silva Filho, Y. Olivier, R. Silbey, J.-L. Brédas, Charge Transport in Organic Semiconductors, Chem. Rev., 107 (2007) 926-952.

[12] J. Roncali, Molecular Bulk Heterojunctions: An Emerging Approach to Organic Solar Cells, Acc. Chem. Res., 42 (2009) 1719-1730.

[13] G. Williams, S. Sutty, H. Aziz, Interplay between efficiency and device architecture for small molecule organic solar cells, Phys. Chem. Chem. Phys., 16 (2014) 11398-11408.

[14] B. Maennig, J. Drechsel, D. Gebeyehu, P. Simon, F. Kozlowski, A. Werner, F. Li, S. Grundmann, S. Sonntag, M. Koch, K. Leo, M. Pfeiffer, H. Hoppe, D. Meissner, N.S. Sariciftci, I. Riedel, V. Dyakonov, J. Parisi, Organic p-i-n solar cells, Appl. Phys. A, 79 (2004) 1-14.

[15] T. Ameri, G. Dennler, C. Lungenschmied, C.J. Brabec, Organic tandem solar cells: A review, Energy Environ. Sci., 2 (2009) 347-363.

[16] J. Hwang, A. Wan, A. Kahn, Energetics of metal-organic interfaces: New experiments and assessment of the field, Materials Science and Engineering: R: Reports, 64 (2009) 1-31.

[17] D. Cahen, A. Kahn, Electron Energetics at Surfaces and Interfaces: Concepts and Experiments, Adv. Mater., 15 (2003) 271-277.

[18] H. Ishii, K. Sugiyama, E. Ito, K. Seki, Energy Level Alignment and Interfacial Electronic Structures at Organic/Metal and Organic/Organic Interfaces, Adv. Mater., 11 (1999) 605-625.

[19] J. Meyer, M. Kröger, S. Hamwi, F. Gnam, T. Riedl, W. Kowalsky, A. Kahn, Charge generation layers comprising transition metal-oxide/organic interfaces: Electronic structure and charge generation mechanism, Appl. Phys. Lett., 96 (2010) 193302.

[20] M.G. Helander, Z.B. Wang, J. Qiu, Z.H. Lu, Band alignment at metal/organic and metal/oxide/organic interfaces, Appl. Phys. Lett., 93 (2008) 193310.

[21] S. Zhong, J.Q. Zhong, H.Y. Mao, J.L. Zhang, J.D. Lin, W. Chen, The role of gap states in the energy level alignment at the organic-organic heterojunction interfaces, Phys. Chem. Chem. Phys., 14 (2012) 14127-14141.

[22] S. Braun, W.R. Salaneck, M. Fahlman, Energy-Level Alignment at Organic/Metal and Organic/Organic Interfaces, Adv. Mater., 21 (2009) 1450-1472.

[23] H.-L. Yip, A.K.Y. Jen, Recent advances in solution-processed interfacial materials for efficient and stable polymer solar cells, Energy Environ. Sci., 5 (2012) 5994-6011.

[24] R. Steim, F.R. Kogler, C.J. Brabec, Interface materials for organic solar cells, J. Mater. Chem., 20 (2010) 24992512.

[25] A. Godoy, L. Cattin, L. Toumi, F.R. Díaz, M.A. del Valle, G.M. Soto, B. Kouskoussa, M. Morsli, K. Benchouk, A. Khelil, J.C. Bernède, Effects of the buffer layer inserted between the transparent conductive oxide anode and the organic electron donor, Sol. Energy Mater. Sol. Cells, 94 (2010) 648-654.

[26] J.C. Bernède, A. Godoy, L. Cattin, F.R. Díaz, M. Morsli, M.A. Del Valle, Organic Solar Cells Perfomances Improvemente Induced by Interface Buffer Layers, in: R.D. Rugescu (Ed.) Solar Energy, Intech, Vukivar, 2010, pp. 223-266. 
[27] M. Mas-Montoya, R.P. Ortiz, D. Curiel, A. Espinosa, M. Allain, A. Facchetti, T.J. Marks, Isomeric carbazolocarbazoles: synthesis, characterization and comparative study in Organic Field Effect Transistors, J. Mater. Chem. C, 1 (2013) 1959-1969.

[28] D. Curiel, M. Mas-Montoya, C.-H. Chang, P.-Y. Chen, C.-W. Tai, A. Tarraga, Multifunctional carbazolocarbazoles as hole transporting and emitting host materials in red phosphorescent OLEDs, J. Mater. Chem. C, 1 (2013) 3421-3429.

[29] D. Curiel, M. Más-Montoya, A. Uruvakili, R.l.A. Orenes, H. Pallamreddy, P. Molina, Synthesis and Characterization of New Carbazolocarbazoles: Toward $\pi$-Extended N-Fused Heteroacenes, Org. Lett., 12 (2010) 3164-3167.

[30] http://www.novaled.com/.

[31] B. Lüssem, M. Riede, K. Leo, Doping of organic semiconductors, Phys. Status Solidi A, 210 (2013) 9-43.

[32] K. Walzer, B. Maennig, M. Pfeiffer, K. Leo, Highly Efficient Organic Devices Based on Electrically Doped Transport Layers, Chem. Rev., 107 (2007) 1233-1271.

[33] J. Wagner, M. Gruber, A. Wilke, Y. Tanaka, K. Topczak, A. Steindamm, U. Hörmann, A. Opitz, Y. Nakayama, H. Ishii, J. Pflaum, N. Koch, W. Brütting, Identification of different origins for s-shaped current voltage characteristics in planar heterojunction organic solar cells, J. Appl. Phys., 111 (2012) 054509.

[34] W. Tress, A. Petrich, M. Hummert, M. Hein, K. Leo, M. Riede, Imbalanced mobilities causing S-shaped IV curves in planar heterojunction organic solar cells, Appl. Phys. Lett., 98 (2011) 063301.

[35] A. Kumar, S. Sista, Y. Yang, Dipole induced anomalous S-shape I-V curves in polymer solar cells, J. Appl. Phys., 105 (2009) 094512

[36] W. Tress, S. Corvers, K. Leo, M. Riede, Investigation of Driving Forces for Charge Extraction in Organic Solar Cells: Transient Photocurrent Measurements on Solar Cells Showing S-Shaped Current-Voltage Characteristics, Adv. Energy Mater., 3 (2013) 873-880.

[37] W. Tress, K. Leo, M. Riede, Influence of Hole-Transport Layers and Donor Materials on Open-Circuit Voltage and Shape of I-V Curves of Organic Solar Cells, Adv. Funct. Mater., 21 (2011) 2140-2149.

[38] J.C. Wang, X.C. Ren, S.Q. Shi, C.W. Leung, P.K.L. Chan, Charge accumulation induced S-shape J-V curves in bilayer heterojunction organic solar cells, Org. Electron., 12 (2011) 880-885.

[39] L. Zuo, J. Yao, H. Li, H. Chen, Assessing the origin of the S-shaped I-V curve in organic solar cells: An improved equivalent circuit model, Sol. Energy Mater. Sol. Cells, 122 (2014) 88-93.

[40] A. Wagenpfahl, D. Rauh, M. Binder, C. Deibel, V. Dyakonov, S-shaped current-voltage characteristics of organic solar devices, Phys. Rev. B, 82 (2010) 115306.

[41] M. Zhang, H. Wang, C.W. Tang, Hole-transport limited S-shaped I-V curves in planar heterojunction organic photovoltaic cells, Appl. Phys. Lett., 99 (2011) 213506.

[42] M. Glatthaar, M. Riede, N. Keegan, K. Sylvester-Hvid, B. Zimmermann, M. Niggemann, A. Hinsch, A. Gombert, Efficiency limiting factors of organic bulk heterojunction solar cells identified by electrical impedance spectroscopy, Sol. Energy Mater. Sol. Cells, 91 (2007) 390-393.

[43] M. Scharnberg, J. Hu, J. Kanzow, K. Rätzke, R. Adelung, F. Faupel, C. Pannemann, U. Hilleringmann, S. Meyer, J. Pflaum, Radiotracer measurements as a sensitive tool for the detection of metal penetration in molecularbased organic electronics, Appl. Phys. Lett., 86 (2005) 024104.

[44] B.P. Rand, J. Li, J. Xue, R.J. Holmes, M.E. Thompson, S.R. Forrest, Organic Double-Heterostructure Photovoltaic Cells Employing Thick Tris(acetylacetonato)ruthenium(III) Exciton-Blocking Layers, Adv. Mater., 17 (2005) 2714-2718.

[45] Z.J. Wang, Y. Wu, Y.C. Zhou, J. Zhou, S.T. Zhang, X.M. Ding, X.Y. Hou, Z.Q. Zhu, Control of carrier transport in organic semiconductors by aluminum doping, Appl. Phys. Lett., 88 (2006) 222112.

[46] C.J. Brabec, A. Cravino, D. Meissner, N.S. Sariciftci, T. Fromherz, M.T. Rispens, L. Sanchez, J.C. Hummelen, Origin of the Open Circuit Voltage of Plastic Solar Cells, Adv. Funct. Mater., 11 (2001) 374-380.

[47] B. Qi, J. Wang, Fill factor in organic solar cells, Phys. Chem. Chem. Phys., 15 (2013) 8972-8982. 